\title{
Hearing and Vestibular Loss with Misuse of Opioids and Illicit Drugs: A Review of the Literature
}

\author{
Michelle L. Hughes ${ }^{a} \quad$ Amanda I. Rodriguez ${ }^{a}$, bonathan Hatch ${ }^{c}$ \\ Kenneth Zouchad \\ aDepartment of Special Education and Communication Disorders, University of Nebraska-Lincoln, Lincoln, NE, \\ USA; ${ }^{b}$ Center for Brain, Biology, and Behavior, University of Nebraska-Lincoln, Lincoln, NE, USA; 'Department of \\ Otolaryngology, University of Nebraska Medical Center, Omaha, NE, USA; ${ }^{d}$ Department of Psychiatry, University of \\ Nebraska Medical Center, Omaha, NE, USA
}

\author{
Keywords \\ Ototoxicity · Hearing loss · Vestibular loss $\cdot$ Opioids · Illicit \\ drugs
}

\begin{abstract}
Background: The purpose of this review was to summarize the literature regarding the effects of opioids and illicit drugs on the auditory and vestibular systems. Methods: Data were sourced from published papers reporting hearing loss (HL) and/or vestibular loss (VL) following misuse or overdose of opioids or illicit drugs. Most papers consisted of retrospective single-case reports, with few retrospective reviews or prospective cohort studies. Search terms included variations of $\mathrm{HL}, \mathrm{VL}$, opioids, and illicit drugs. Search results yielded 51 articles published between 1976 and 2021. A total of 44 articles were reviewed after excluding studies that were not available in English ( $n=3$ ), only described acute effects in healthy cohorts $(n=3)$ or only described general health aspects in a group on methadone maintenance $(n=1)$. Results: Sixteen studies reported ototoxicity from illicit drugs, 27 from prescription opioids, and 1 was unspecified. This review shows that $\mathrm{HL}$ associated with amphetamines and cocaine was typically sudden, bilateral, and temporary. HL from co-
\end{abstract}

caine/crack and heroin often presented with greatest losses in the mid-frequency range. HL associated with opioids was typically sudden, bilateral, moderately severe to profound, and in most cases permanent. The literature is sparse regarding VL from illicit drugs and opioids. Conclusion: Practitioners who see patients for sudden or rapidly progressive HL or VL with no apparent cause should inquire about misuse of illicit drugs and opioids, particularly when the $\mathrm{HL}$ does not respond to steroid treatment.

(c) 2022 S. Karger AG, Basel

\section{Introduction}

Ototoxicity presents with a myriad of symptoms including hearing loss (HL), tinnitus, aural fullness, hyperacusis, imbalance, and/or vertigo. Ototoxicity is known to result from medications used to treat conditions such as cancer, infection, and kidney disease. Commonly recognized ototoxic medications include aminoglycoside and macrolide antibiotics, loop diuretics, platinum-based chemotherapeutics, antimalarials, salicylates, and nonsteroidal anti-inflammatories [e.g., D'Alonzo and Cantor, 1983; Roland and Rutka, 2004; Rybak and Ramku-
Karger@karger.com www.karger.com/aud (c) 2022 S. Karger AG, Base
Correspondence to:

Michelle L.Hughes, mhughes3@unl.edu

$$
\text { 는 }
$$ \\ Karger"}


mar, 2007; Ding et al., 2016; dos Santos et al., 2020]. Accumulating case reports describe ototoxic effects resulting from misuse of opioids and illicit drugs, yet many healthcare professionals are not aware of the audiological and vestibular impacts of these substances. In fact, opioids and illicit drugs have been included in some publications listing ototoxic substances within the past decade [e.g., Cianfrone et al., 2011], but not included in others [e.g., Bisht and Bist, 2011]. Given the current opioid epidemic, it is important for healthcare providers to understand which of these substances can result in ototoxicity, which otologic systems are affected (auditory and/or vestibular), and whether ototoxic effects are likely to be temporary or permanent. A more in-depth understanding of substance misuse-related HL or vestibular loss (VL) would guide otolaryngologists' decisions for medical management referrals (i.e., addiction medicine) or alternative treatment interventions for postoperative pain control [Anne et al., 2021], particularly in patients at risk for substance misuse.

When patients are prescribed known ototoxic medications, audiologists perform ototoxicity monitoring that focuses on high frequencies because damage generally manifests first at the basal end of the cochlea [e.g., Fausti et al., 2003; Fausti et al., 2007; Konrad-Martin et al., 2014]. Vestibular function is rarely assessed as part of ototoxicity monitoring protocols [Ganesan et al., 2018]. Interestingly, opioids and illicit drugs are typically not included as causative substances in ototoxicity training in audiology, medical school, or residency programs. Additionally, there may be a missed opportunity to identify connections between ototoxicity and substance misuse because healthcare providers do not generally ask patients about the use of illicit or opioid drug use in the context of hearing or vestibular complaints, or vice versa. Specifically, otolaryngologists may not ask questions about illicit drug use or prescription opioid misuse for patients presenting with sudden sensorineural HL (SSNHL) and who do not respond to traditional steroid treatment. Conversely, physicians who work in addiction medicine may not routinely ask questions about hearing and vestibular function. Emergency medicine physicians are often the first to encounter patients with a drug overdose, but also do not query about hearing or vestibular function [Kopec and Nelson, 2012]. Thus, there is an overall disconnect in the case history process, mediated by a lack of widespread knowledge of the link between substance misuse and HL or VL.

Drug overdoses are the leading cause of injury-related death in the USA [Mack et al., 2017], with >70\% in 2019 involving opioids [CDC, 2020]. In 2019, an estimated 57.2 million Americans had used illicit drugs in the past year, including 9.7 million who misused prescription pain medications [SAMHSA, 2020]. There are approximately 20.4 million people in the USA who have a substance use disorder, and of the 1.6 million who have an opioid use disorder, only $18 \%$ received medication for it [SAMHSA, 2020]. In the USA, the opioid dispensing rate peaked in 2012 at 81.3 prescriptions per 100 people, or $>255$ million total prescriptions, excluding mail-order prescriptions and methadone treatment [CDC, 2021]. Worldwide, an estimated 35 million people between the ages of 15 and 65 years misuse opioids [Oroei et al., 2018]. Given the alarming public health burden of drug misuse, there is an increased likelihood that otolaryngologists and audiologists will encounter individuals with significant substance misuse histories. Unfortunately, little is known about the incidence of HL and VL in individuals who misuse illicit drugs and/or opioids. Furthermore, it is unclear what factors lead to temporary versus permanent loss and what underlying physiological mechanisms are responsible. Thus, the purpose of this review is to better understand from the existing literature which of these substances can result in ototoxicity, which otologic systems are affected (auditory and/or vestibular), and whether ototoxic effects are likely to be temporary or permanent. By gaining a more thorough understanding of these issues, clinicians will be better equipped to query, manage, and make appropriate referrals for individuals who present with a history of substance misuse and be better equipped to include detailed questions about opioid and illicit drug use for patients who present with sudden or otherwise unexplained HL or VL.

\section{Methods}

A literature search was conducted using PubMed and Google Scholar without restrictions on publication dates. Search terms included combined variations of HL, deafness, VL, vestibular dysfunction, vestibular hypofunction, vestibulopathy, illicit drugs, and opioids. Articles identified in the search results were crosschecked against relevant references within the identified papers. Search results yielded 51 articles published between 1976 and 2021. Three articles were excluded because they were not available in English [Mulch and Handrock, 1979; Lindeman et al., 2014; Pingarrón et al., 2014], 2 more were excluded because they examined acute vestibular effects of fentanyl in healthy cohorts only [Rottach et al., 2002; Ramaioli et al., 2014], and one was excluded because it only reported general health characteristics of heroin users in a methadone maintenance program [Du et al., 2008]. Most studies consisted of case reports; therefore, a meta-analysis could not be conducted. The resulting 44 studies are discussed below. 
Table 1. Summary of studies reporting illicit drugs' and opioids' ototoxic effects

\begin{tabular}{lllll}
\hline Drug & $\begin{array}{l}\text { Studies, } \\
n\end{array}$ & $\begin{array}{l}\text { Patients with } \\
\text { hearing loss, } n\end{array}$ & $\begin{array}{l}\text { Patients with } \\
\text { tinnitus, } n\end{array}$ & $\begin{array}{l}\text { Patients with vestibular } \\
\text { symptoms, } n\end{array}$ \\
\hline Illicit & $16^{*}$ & & & \\
$\quad$ Amphetamine & 2 & 27 & 1 & - \\
Cocaine & 2 & 2 & - & - \\
Cannabis & 1 & 1 & 2 & 2 \\
Heroin & 7 & 8 & 5 & 49 \\
Multi illicit & 6 & 5 & 15 & 28 \\
Opioids & 27 & & 23 & 6 \\
General opioids & 10 & 34 & 3 & 2 \\
$\quad$ Opioid + acetaminophen & 7 & 30 & 21 & \\
Methadone/propoxyphene & 10 & & & \\
\hline
\end{tabular}

Dashes represent information that was not reported. * Iqbal [2002b] reported findings for 3 different drugs (amphetamines, cannabis, and heroin) in a single publication.

\section{Results}

\section{Overview of the Literature}

Of the 44 studies, 16 (37\%) reported ototoxicity related to illicit drug ingestion comprised of amphetamines [Iqbal, 2002a, b], cocaine [Ciorba et al., 2009; Stenner et al., 2009], cannabis [Iqbal, 2002b], heroin [Polpathapee et al., 1984; Ishiyama et al., 2001; Iqbal, 2002b; Kortequee et al., 2005; Schrock et al., 2008; Antonopoulos et al., 2012; Aulet et al., 2014], or a combination of drugs [Sharma, 2001; Nicoucar et al., 2005; Fowler and King, 2008; Nair et al., 2010; Schweitzer et al., 2011; Moreira et al., 2012]. One additional study [Józefowicz-Korczynska et al., 1994] reported vestibular and audiometric results for people addicted to "drugs" that were not specified beyond noting inclusion of opiates, barbiturates, and inhalants. The remaining 27 studies (61\%) reported ototoxicity from prescription of opioids including morphine, oxymorphone, hydrocodone, oxycodone [Kurnatowski and Garganisz, 1996; Ho et al., 2007; Rawool and Dluhy, 2011; Kopec and Nelson, 2012; Boyle and Rosenbaum, 2013; Helander et al., 2014; MacDonald et al., 2015; Leache et al., 2016; Ntranos et al., 2017; Mozeika et al., 2020], the combination of an opioid (hydrocodone, codeine, oxycodone, or dextropropoxyphene) and acetaminophen [Ramsay, 1991; Friedman et al., 2000; Oh et al., 2000; Blakley and Schilling, 2008; Rigby and Parnes, 2008; Freeman et al., 2009; Novac et al., 2015], and maintenance medications that included methadone or propoxyphene [Lupin and Harley, 1976; Harell et al., 1978; van Gaalen et al., 2009; Christenson and Marjala, 2010; Shaw et al., 2011; Vora- subin et al., 2013; Bayat et al., 2019; Ghasemi et al., 2019; Repple et al., 2021].

Substance types are summarized in Table 1, along with the total number of patients reporting either HL or VL. Most publications (35/44 or $79.5 \%$ ) were case reports of 1-9 patients. Of the remaining 9 studies (20\%) involving larger cohorts, 2 reported results for use of illicit drugs [Iqbal, 2002b; Moreira et al., 2012], 6 reported on misuse of prescription opioids [Kurnatowski and Garganisz, 1996; Friedman et al., 2000; Freeman et al., 2009; Rawool and Dluhy, 2011; Bayat et al., 2019; Mozeika et al., 2020], and 1 reported on "drugs" that included both opioids and illicit substances [Józefowicz-Korczynska et al., 1994]. Results from Józefowicz-Korczynska et al. [1994] are not included in Table 1 because data for all substances were reported in aggregate. The results of these studies are discussed in the following sections, categorized by either illicit drugs or prescription opioids. Figure 1 summarizes all reports of HL (Fig. 1a) and VL (Fig. 1b) across 43 of the 44 studies by substance type, excluding the data from Jozefowicz-Korczynska et al. [1994]. In all cases, HL was either documented as or presumed to be sensorineural in nature.

\section{Illicit Drugs}

For amphetamines, 2 studies on a total of 27 men reported HL that was sudden, bilateral, and temporary in all cases [Iqbal, 2002a, b]. Hearing recovered within a few days to up to 10 days. HL and subsequent resolution were self-report only and not verified audiometrically; therefore, it is unclear whether any residual high-frequency HL remained. The degree of HL was not specified, and ves- 
Fig. 1. a Number of patients reported in the literature having either permanent or temporary HL following misuse of illicit or opioid drugs. b Number of reporting vestibular symptoms/abnormal test results versus denying vestibular symptoms.

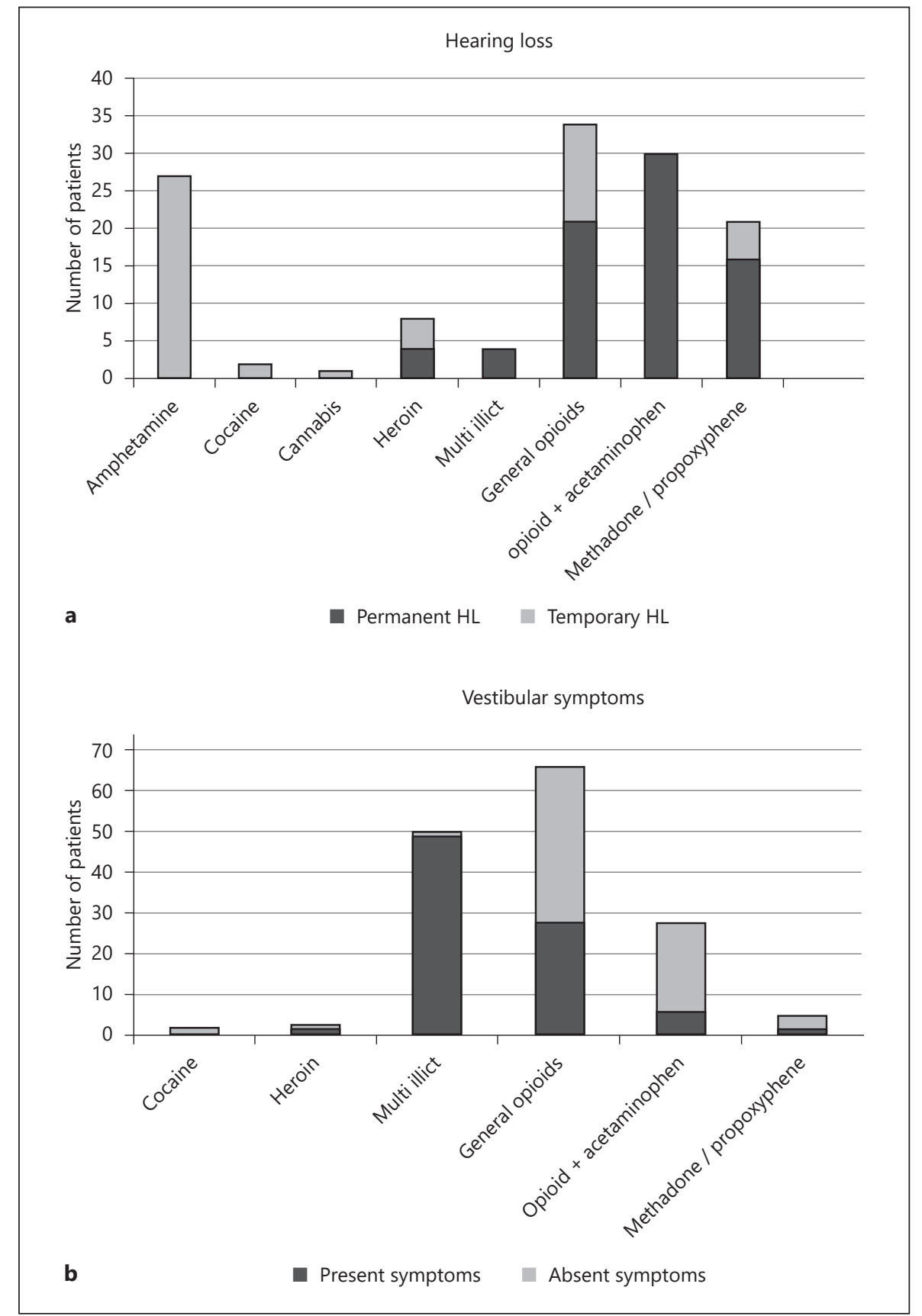

tibular results were not reported. Proposed mechanisms for the HL were transient temporal lobe ischemia or changes in neural signaling through depletion of neurotransmitters.

For the 2 case studies involving cocaine, the HL was sudden, moderate to severe, bilateral, and temporary, resolving within 3 days [Stenner et al., 2009] to 1 month [Ciorba et al., 2009]. In both cases, the patients denied vestibular symptoms. Crack/cocaine can cause permanent damage to neural structures including myelin and neurotransmitters [Weich et al., 2012]; however, this would not explain the transient nature of the HL. Ciorba et al. [2009] proposed the HL was potentially due to a disruption in the endocochlear potential because cocaine is a fast $\mathrm{K}+$ channel blocker. 


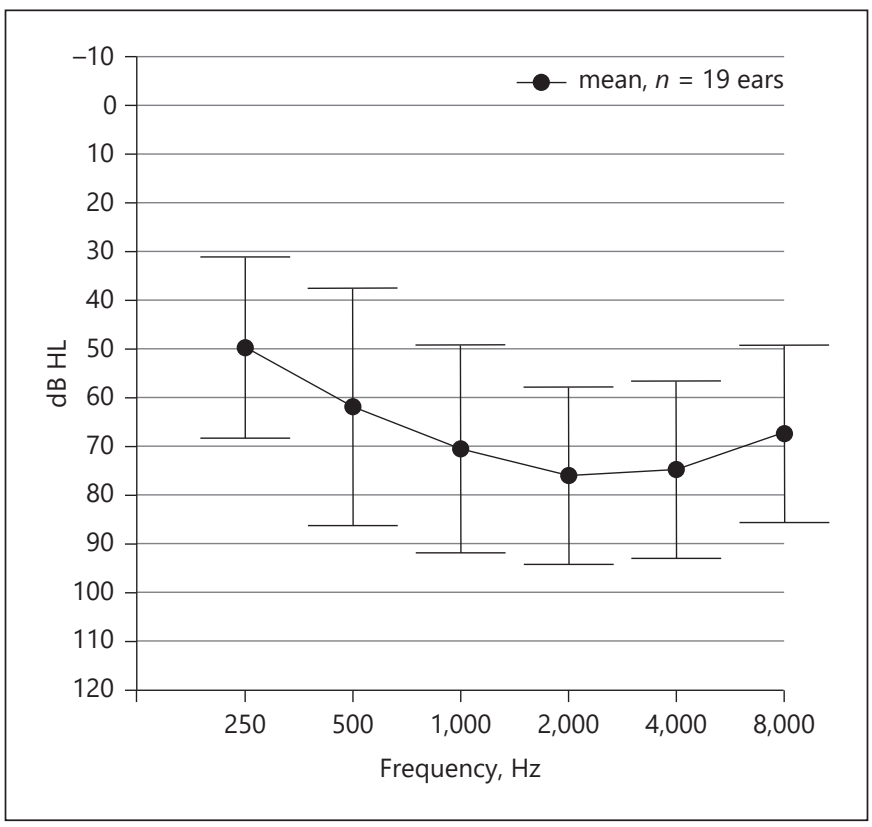

Fig. 2. Mean $( \pm 1$ SD) audiometric thresholds for 19 ears in 10 patients ( 1 with unilateral HL) resulting from misuse of cocaine/ crack and/or heroin.

For the 7 case studies involving heroin, all 8 patients presented with SSNHL ranging from moderately severe to profound HL [Polpathapee et al., 1984; Ishiyama et al., 2001; Iqbal, 2002b; Kortequee et al., 2005; Schrock et al., 2008; Antonopoulos et al., 2012; Aulet et al., 2014]. HL was bilateral for all but 1 patient who had injected heroin into his neck, in which case the profound permanent HL was on the side injected [Kortequee et al., 2005]. Hearing fully recovered for 4 patients, partially recovered for 2 , and did not improve for 2 . Tinnitus was reported for 2 patients, denied for 2 patients, and not reported for the rest. Two patients presented with vestibular symptoms, both of which resolved [Ishiyama et al., 2001; Kortequee et al., 2005]. Interestingly, in 4 cases, patients had chronically used heroin, went through a period of abstinence, and then relapsed with an overdose resulting in the SSNHL [Polpathapee et al., 1984; Ishiyama et al., 2001; Schrock et al., 2008; Antonopoulos et al., 2012]. HL was temporary for 2 of those patients, partially recovered for 1 , and permanent for 1 .

It is unclear what mechanisms contribute to heroininduced HL. Proposed etiologies include changes in sensitivity to opioid receptors in the cochlea [Ishiyama et al., 2001], cochlear and central auditory damage [Polpathapee et al., 1984], or ototoxic additives to heroin such as quinine, which can cause temporary HL [Schrock et al., 2008; Antonopoulos et al., 2012; Aulet et al., 2014]. Antonopoulos et al. [2012] reported a mild sloping to moderately severe SNHL in a patient who had overdosed on heroin. Otoacoustic emissions were absent, as would be expected for this degree of HL; however, auditory brainstem responses were also absent at $105 \mathrm{~dB}$ nHL suggesting both cochlear and retrocochlear effects. Only one study reported HL with cannabis use [Iqbal, 2002b], which was bilateral, sudden, and temporary, with no report regarding vestibular function or degree of HL.

Six studies reported misuse of multiple combined illicit drugs. Five were single-case studies involving combinations of cocaine/crack and either heroin or methadone [Nicoucar et al., 2005; Fowler and King, 2008; Nair et al., 2010], heroin and benzodiazepines [Schweitzer et al., 2011], or ecstasy (also known as MDMA, an amphetamine derivative similar to methamphetamine that is combined with a hallucinogen) with methadone [Sharma, 2001]. All patients in these single-case studies experienced SSNHL, with the majority experiencing bilateral loss (4/5), and tinnitus (5/5). The degree of HL ranged from mild-moderate to profound. HL was permanent for most (4/5), despite some improvement in 3 of those patients, whereas it was unknown whether hearing recovered in 1 case [Fowler and King, 2008]. In the 1 case with unilateral SSNHL [Nicoucar et al., 2005], ingestion was intranasal resulting in a permanent SNHL due to an intralabyrinthine hemorrhage found on magnetic resonance imaging. Of the 5 cases, 2 patients reported dizziness [Sharma et al., 2001; Nicoucar et al., 2005], 1 patient denied vestibular symptoms [Schweitzer et al., 2011], and the remaining cases did not report on vestibular function [Fowler and King, 2008; Nair et al., 2010]. Only one cohort study for various illicit drugs [Moreira et al., 2012] has reported objective vestibular testing. In a group of 47 people who used marijuana and/or cocaine/crack with alcohol compared to a healthy control group of 47 people, Moreira et al. [2012] utilized computerized electronystagmography to measure pendular tracking, optokinetic, and spontaneous, positional, and positioning nystagmus. A pendular rotary and caloric test was included with stimuli not described. Functional balance was measured using a dynamic posturography unit. Of the 47 users of illicit drugs, 46 reported vestibular symptoms, but $43 \mathrm{had}$ normal findings, whereas 4 had reduced caloric responses consistent with peripheral dysfunction. However, overall mean sway on posturography and for visual-vestibular specific test conditions showed lower balance stability for the group of illicit drug users when compared to 
the control group, suggestive to the authors that illicit drugs disrupt central pathway integration of visual, vestibular, and visual-vestibular stimuli. Audiometric results were not reported in that study.

Of the 16 studies involving illicit drugs, 11 had published patient audiograms. Ten of these were for cocaine/ crack and/or heroin. One interesting observation emerged among this group, which has not been reported previously. Many patients presented with cookie-bite audiograms (mid-frequency SNHL, or MFSNHL), with the maximum HL occurring between 1 and $4 \mathrm{kHz}$. Figure 2 shows the mean $( \pm 1 \mathrm{SD})$ audiometric thresholds estimated from the published audiograms for 19 ears in 10 patients (1 had unilateral HL). This pattern conflicts with traditional ototoxicity-induced HL where the highest frequencies are affected first, suggesting that the mechanisms involved differ from those that cause HL for common ototoxic medications. MFSNHL is uncommon, accounting for $<1 \%$ of all HL patterns [Shah et al., 2005] and $5 \%$ of all SSNHL [Young, 2020]. MFSNHL is most often attributed to genetic non-syndromic etiologies [Martini et al., 1997; Shah et al., 2005; Xia et al., 2016; Yamamoto et al., 2017], with approximately $22 \%$ of cases attributed to small vestibular schwannomas [Saunders et al., 1995]. Of the 10 patients represented in Figure 2, word recognition scores were reported for 4 of them [Polpathapee et al., 1984; Nair et al., 2010; Schweitzer et al., 2011; Aulet et al., 2014]. In all 4 cases, scores were symmetrical between ears and ranged from $4 \%$ [Aulet et al., 2014] to $80 \%$ [Schweitzer et al., 2011].

\section{Prescription Opioids}

Of the 27 studies reporting ototoxicity following misuse of prescription opioids, 16 reported on single cases, 5 reported on a series of cases (2-9 patients), and 6 reported on cohorts of 10 or larger. Across the 21 studies reporting on single or multiple individual cases involving opioids, HL was temporary for 11 individuals and permanent for 20, with the largest percentage of permanent HL occurring for individuals who had misused opioid-acetaminophen combinations (100\%). In most cases, HL secondary to opioid misuse presented with a sudden or rapidly progressive onset, and steroid treatment was usually ineffective [Oh et al., 2000].

Mozeika et al. [2020] published the most comprehensive and largest study to date focusing on HL with opioid misuse. Data were collected from 2 decades of information contained in New Jersey's statewide poison center database. Of 41 individuals presenting with hearing complaints time locked with opioid use, $29 \%$ became deaf,
$36 \%$ sustained HL, 24\% experienced tinnitus, and 10\% reported a combination of some degree of HL and tinnitus. However, it did not appear that audiograms were completed, as "auditory dysfunction" was based on subjective reports in the medical record. In all but 1 case, HL occurred bilaterally. Of these 41 individuals, there were additional outcomes on only 19 at the time of hospital discharge. HL was reported as completely resolved for 7 individuals, partially resolved for 8 , and unresolved for 4 . Again, it was unclear whether these results were based on audiometric testing or subjective reports. Vestibular function was not addressed in the study.

Rawool and Dluhy [2011] reported on the incidence of HL in 23 men who used unspecified opioids with or without a history of noise exposure. Of this group, only 4 did not have a history of either hobby or occupational noise exposure, and 2 of those had HL. Vestibular function was not addressed. Bayat et al. [2019] reported permanent bilateral HL in a group of 11 of 27 men in a treatment program undergoing methadone maintenance. HL onset (sudden vs. progressive), degree, and vestibular function were not reported.

Friedman et al. [2000] reported on 12 patients with permanent profound SNHL stemming from a hydrocodone-acetaminophen combination. In all cases, HL was sudden or rapidly progressive and was bilateral for $8 / 12$ patients. Only 2 patients reported vestibular symptoms at the time of the HL. Eight patients subsequently received cochlear implants (CIs). Neither dosage nor duration of use reportedly predicted the degree of $\mathrm{HL}$ at onset, rate of progression (sudden vs. rapidly progressive), or symmetry.

Freeman et al. [2009] reported on 10 individuals who took excessive amounts of codeine and acetaminophen resulting in bilateral profound deafness leading to subsequent cochlear implantation. Notably, all patients presented with their highest mean corpuscular volume at a time that coincided with their sudden or rapidly progressive HL. Given the microvascular structures within the cochlea, the authors speculated that the HL may have resulted from a vascular pathology. Despite the rapid progression of severe/profound HL, 9/10 patients denied vestibular symptoms, and all had normal vestibular test results, which aligns with the greater sensitivity of the cochlea to vascular flow than the vestibule.

Across all studies involving prescription opioids, 28 of 67 people (42\%) who sustained permanent HL received CIs. CIs have been shown to work well for those who experienced permanent severe-profound HL secondary to opioid use, so the locus is presumed to be cochlear [Ho et 
al., 2007; Blakley and Schilling, 2008; Freeman et al., 2009]. The underlying cause of opioid-induced HL, however, is not known. Potential mechanisms have been proposed, including ischemic damage, hypoxic changes within the cochlea, genetic variations in metabolic processes, or effects on homeostasis such as a disruption of the endocochlear potential [Kopec and Nelson, 2012; Saifan et al., 2013; Oroei et al., 2018; Bayat et al., 2019]. Given the heterogeneity of onset, degree, and symmetry among cases, individual differences could be mediated by type of substance(s) used, age, gender, route of ingestion (e.g., oral, injected, inhaled), genetic and metabolic factors, and comorbid medical conditions such as cardiac or renal failure [Ganesan et al., 2018]. As noted earlier, however, Freeman et al. [2009] found that neither dosage nor duration of use appeared to predict onset, degree, or symmetry.

Using mouse models, Yorgason et al. [2010] found that acetaminophen - rather than hydrocodone - is the primary ototoxic agent in Vicodin ${ }^{\circledR}$ (Knoll Labs, Mt. Olive, NJ, USA), with HL resulting primarily from oxidative and endoplasmic reticulum stress [Kalinec et al., 2014]. Yorgason et al. [2010] also stated that acetaminophen ototoxicity was potentiated by hydrocodone and suggested acetaminophen may work synergistically with hydrocodone to damage auditory cells. These findings contradict earlier sources noting no published reports of ototoxicity resulting strictly from acetaminophen [LonsburyMartin and Martin, 2007]. However, HL has resulted from many different types of opioids (unpaired with acetaminophen), which may implicate compromised function of opioid receptors in the cochlea [Ishiyama et al., 2001; Kopec and Nelson, 2012; Mozeika et al., 2020], as all 3 opioid receptors are found in the human cochlea. In many of the single case studies, vestibular symptoms were less documented as compared to auditory effects, suggesting potential differential effects of opioid use on the auditory and vestibular systems. However, vestibular function results were not always published or information on the assessments used was minimal.

One large-cohort study [Józefowicz-Korczynska et al., 1994] involving 96 males aged 15-35 years addicted to "drugs" reported HL in 112 ears in 62 (65\%) patients. Comprehensive vestibular testing revealed an abnormal caloric finding (e.g., high directional preponderance, reduced total beats of nystagmus, caloric weakness) for 88 (92\%) patients. Overall, electronystagmography with caloric results indicated peripheral vestibular involvement for 20 (25\%) individuals and central involvement for 59 (61\%). Results were not considered in the context of sub-

Hearing and Vestibular Loss with Drug Misuse stance type, other than a statement noting that substances such as opiates, barbiturates, and inhalants were used. Therefore, it is unclear which substances were associated with HL or VL.

Finally, a large cohort study [Kurnatowski and Garganisz, 1996] involving 62 adults (predominately men) who had past unspecified opioid misuse and in treatment and 50 healthy volunteers received comprehensive vestibular testing using electronystagmography. Within the group with past opioid use, 24 reported vestibular symptoms, 12 (19\%) had peripheral vestibular dysfunction (e.g., caloric weakness, horizontal positional nystagmus), and 43 (69\%) had signs of central vestibular dysfunction (e.g., poor ocular motility, cerebellar signs), with overall significant vestibular outcome differences when compared to the healthy volunteer group. Objective hearing outcomes were not obtained in this study.

\section{Limitations}

Several limitations in the current literature make it difficult to fully understand the incidence and impacts of substance misuse on the inner ear. First, most studies relied on self-reports of HL. Approximately half of the studies that reported HL secondary to substance use either did not obtain audiometric results, or if they did have testing done, the results were not published. It is therefore unclear whether the nature of the HL was sensorineural, as they were presumed. It is also unclear what the degree of HL was, as some case studies solely reported that patients stated they "couldn't hear."

Second, it is unclear in cases reporting recovery of HL whether the hearing fully recovered. All studies were retrospective, so there were no baseline audiograms prior to substance use or prior to the complaint of HL. Additionally, it is more common for people to be unaware of the presence of high-frequency HL. Because ototoxicity typically begins with damage to the basal end of the cochlea, it is possible that patients had residual high-frequency HL in cases where HL reportedly recovered.

Third, vestibular symptoms were not reported in half (22 of 44) of the studies. In most of the studies that reported normal vestibular function, approximately $50 \%$ did not report formal results from clinical vestibular assessments. Even when results were provided, assessments were either specific to only the semicircular canal (whereas other vestibular end-organ deficits are possible) or only included a measure of balance, which cannot isolate the inner ear. Due to the proximity of the cochlea and vestibule, along with the similarity of some of the structures, 
it is possible that substances might affect both the hearing and vestibular systems with different severities. Notably, research suggests that individuals with SNHL often have concomitant saccular dysfunction in the same ear. The mechanisms proposed are the cochlea and saccule's common embryologic origin in the pars inferior of the labyrinth, noise exposure effects, and/or ischemic changes given that the cochlea and saccule share a common arterial supply [Zuniga et al., 2012]. However, because the peripheral vestibular pathology can compensate at the level of the cerebellar vestibular nuclei, it is possible that VL could still exist in patients without being functionally noticed until the loss has progressed. Without more objective and comprehensive vestibular testing, the true prevalence of VL associated with substance misuse is likely underreported.

Fourth, it is unclear how the incidence of SSNHL in people who misuse substances - particularly in cases of overdose - differs from that of the general population. In a large cross-sectional study examining data from over 60 million insured patients, Alexander and Harris [2013] reported the incidence of idiopathic SSNHL was 27 per 10,000 per year for data spanning 2006-2007. This number included both inpatient and outpatient claims. The etiology of SSNHL is unknown in approximately $70 \%$ of cases [Chau et al., 2010]. To focus on the unknown etiologies, the study excluded individuals with concomitant diagnoses that were associated with known SSNHL such as Meniere's disease, vestibular schwannoma, labyrinthine fistula, noise-induced HL, and congenital HL. They found the incidence of SSNHL increased with age, and men were slightly more likely than women to experience SSNHL. The authors theorized these age and gender trends might be attributed to the increased risk of vascular events in men and in the elderly. One limitation of the study is that the data were obtained through a medical and pharmaceutical claims database, and therefore did not capture health conditions in uninsured people. This is important because illicit drug use increases the risk of being uninsured [Wang and Xie, 2017]. Additionally, it is unclear the extent to which their data captured individuals who misuse substances, as other codes related to addiction or overdose were not considered. The incidence of SSNHL in people who misuse illicit drugs and prescription opioids is unclear.

Last, the type of substances used was typically self-reported, although toxicology tests were run in some cases. In cases where multiple substances were used, it is difficult to know which were involved in causing hearing or vestibular dysfunction. Furthermore, it is known that il- licit drugs can contain impurities such as quinine, metals, or organic solvents [Iqbal, 2002a; Antonopoulos et al., 2012], which also can be ototoxic.

\section{Implications for Clinical Practice}

A multidisciplinary approach is recommended when patients present with hearing or vestibular complaints especially of sudden onset - coupled with a positive history of substance misuse. For many of the case reports presented here, patients were first evaluated in the emergency department. These patients might be seen by otolaryngology during admission or for follow-up after discharge. This review shows that HL associated with amphetamines and cocaine was typically sudden, bilateral, and temporary. HL associated with opioids was usually sudden, bilateral, moderately severe to profound, and in most cases, permanent. Therefore, otologists and otolaryngologists who see patients for sudden or rapidly progressive HL or VL with no apparent cause should inquire about misuse of illicit drugs and opioids, particularly when the HL does not respond to steroid treatment. If a patient's history is positive for substance misuse, a referral should be made to addiction medicine for further management, regardless of whether the HL resolves. Likewise, practitioners working in pain or addiction medicine, methadone maintenance clinics, or other treatment centers should include screening questions about HL, tinnitus, aural fullness, and dizziness that may warrant audiological or otologic referral.

Certain groups who are at risk for HL are also at higher risk for opioid misuse, such as military veterans, older adults, and workers in manual-labor jobs [Rigg and Rigg, 2020]. These groups have a high rate of being prescribed opioids for pain management. Additionally, veterans are at higher risk for noise-induced HL, older adults are at higher risk for age-related $\mathrm{HL}$, and manual-labor workers are at higher risk for exposure to hazardous noise and ototoxic agents [Rigg and Rigg, 2020]. Therefore, detailed case histories should identify individuals who have a high risk of age- or noise-related HL and potential for opioid misuse.

It is unclear how much healthcare providers know about ototoxicity effects secondary to illicit drug use or misuse of prescribed opioids. Many of the publications covered in this review noted that HL is a rare adverse effect associated with illicit drug use. However, in 2007, Ho et al. [2007] described opioid-induced ototoxicity as "infrequently recognized," whereas more recently, Mozeika et al. [2020] described it as "a known complication." Thus, there is a need for increased awareness of illicit- and opi- 
oid-induced ototoxicity across disciplines spanning otolaryngology, audiology, pain, addiction, and emergency medicine.

\section{Conclusion}

Although the number of reports of HL and/or VL secondary to misuse of illicit drugs and opioids has increased over the past 2 decades, systematic research regarding prevalence and outcomes is lacking. Practitioners who see patients for unexplained sudden or rapidly progressive HL or VL should inquire about misuse of illicit drugs and opioids, especially if steroid treatment is not effective.

\section{Statement of Ethics}

An ethics statement is not applicable because this study is based exclusively on published literature.

\section{Conflict of Interest Statement}

Michelle L. Hughes is an employee of the University of Nebraska-Lincoln; has a courtesy appointment at the University of Nebraska Medical Center; has current and past grant funding from the National Institutes of Health (NIH), the University of Nebraska Tobacco Settlement Biomedical Research Fund, and the Rural Drug Addiction Research Center; receives honoraria from the $\mathrm{NIH}$ as a member of the Communication Disorders Review Committee; and receives royalties from Plural Publishing. Amanda I. Rodriguez is an employee of the University of Nebraska-Lincoln and has current grant funding from the University of Nebraska Tobacco Settlement Biomedical Research Fund and the Rural Drug Addiction Research Center. Jonathan Hatch is an employee of the University of Nebraska Medical Center with current NIH funding. Kenneth Zoucha is an employee of the University of Nebraska Medical Center and has current funding from the Nebraska Department of Health and Human Services and the Rural Drug Addiction Research Center.

\section{Funding Sources}

This study was funded by the Nebraska Tobacco Settlement Biomedical Research Development Funds and supported by the Rural Drug Addiction Research Center (NIH COBRE: P20GM130461). The funding bodies did not have a role in the preparation of this manuscript.

\section{Author Contributions}

Michelle L. Hughes: conception and study design, literature review, and synthesis, figure preparation, manuscript writing; Amanda I. Rodriguez: conception and study design, literature review and synthesis, critical review, and editing of manuscript; Jonathan Hatch: data interpretation, critical review, and editing of manuscript; Kenneth Zoucha: data interpretation, critical review, and editing of manuscript.

\section{Data Availability Statement}

All data from this study are available from the published sources listed in the References section. Further inquiries can be directed to the corresponding author.

\section{References}

Alexander TH, Harris JP. Incidence of sudden sensorineural hearing loss. Otol Neurotol. 2013;34:1586-9.

Anne S, Mims JW, Tunkel DE, Rosenfeld RM, Boisoneau DS, Brenner MJ, et al. Clinical practice guideline: opioid prescribing for analgesia after common otolaryngology operations. Otolaryngol Head Neck Surg. 2021; 164(2_Suppl):S1-42.

Antonopoulos S, Balatsouras DG, Kanakaki S, Dona A, Spiliopoulou C, Giannoulis G. Bilateral sudden sensorineural hearing loss caused by alcohol abuse and heroin sniffing. Auris Nasus Larynx. 2012;39(3):305-9.

Aulet RM, Flis D, Sillman J. A case of heroin induced sensorineural hearing loss. Case Rep Otolaryngol. 2014;2014:962759.

Bayat A, Saki N, Mirmomeni G, Yadollahpour A. Early diagnosis of hearing loss in patients under methadone maintenance treatment. Front Neurol. 2019;10:749.
Bisht M, Bist SS. Ototoxicity: the hidden menace. Indian J Otolaryngol Head Neck Surg. 2011; 63(3):255-9.

Blakley BW, Schilling H. Deafness associated with acetaminophen and codeine abuse. J Otolaryngol Head Neck Surg. 2008;37(4):507-9.

Boyle KL, Rosenbaum CD. Oxymorphone insufflation associated with acute sensorineural hearing loss: case files of the University of Massachusetts Medical Toxicology Fellowship. J Med Toxicol. 2013;9(2):179-83.

Centers for Disease Control and Prevention. U.S. opioid dispensing rate maps [internet]. 2020 Dec 7. Available from: https://www.cdc.gov/ drugoverdose/maps/rxrate-maps.html Accessed 2021 Apr 19.

Centers for Disease Control and Prevention. Understanding the epidemic [internet]. 2021 Mar 17. Available from: https://www.cdc. gov/drugoverdose/epidemic/index.html Accessed 2021 Apr 19.
Chau JK, Lin JR, Atashband S, Irvine RA, Westerberg BD. Systematic review of the evidence for the etiology of adult sudden sensorineural hearing loss. Laryngoscope. 2010;120:101121.

Christenson BJ, Marjala AR. Two cases of sudden sensorineural hearing loss after methadone overdose. Ann Pharmacother. 2010;44(1): 207-10.

Cianfrone G, Pentangelo D, Cianfrone F, Mazzei F, Turchetta R, Orlando M, et al. Pharmacological drugs inducing ototoxicity, vestibular symptoms and tinnitus: a reasoned and updated guide. Eur Rev Med Pharmacol Sci. 2011;15(6):601-36.

Ciorba A, Bovo R, Prosser S, Martini A. Considerations on the physiopathological mechanism of inner ear damage induced by intravenous cocaine abuse: cues from a case report. Auris Nasus Larynx. 2009;36(2):213-7. 
D’Alonzo BJ, Cantor AB. Ototoxicity: etiology and issues. J Fam Pract. 1983;16(3):489-94.

Ding D, Liu H, Qi W, Jiang H, Li Y, Wu X, et al. Ototoxic effects and mechanisms of loop diuretics. J Otol. 2016;11(4):145-56.

dos Santos NAG, Ferreira RS, dos Santos AC. Overview of cisplatin-induced neurotoxicity and ototoxicity, and the protective agents. Food Chem Toxicol. 2020;136:111079.

Du W-J, Xiang Y-T, Wang Z-M, Chi Y, Zheng Y, Luo X-N, et al. Socio-demographic and clinical characteristics of 3129 heroin users in the first methadone maintenance treatment clinic in China. Drug Alcohol Depend. 2008;94(13):158-64.

Fausti SA, Helt WJ, Phillips DS, Gordon JS, Bratt GW, Sugiura KM, et al. Early detection of ototoxicity using 1/6th-octave steps. J Am Acad Audiol. 2003;14(8):444-50.

Fausti SA, Reavis KM, Helt WJ, Phillips DS, Gordon JS, Konrad-Martin DL. Audiologic monitoring for ototoxicity and patient management. In: Campbell KCM, editor. Pharmacology and ototoxicity for audiologists. Thompson Delmar Learning; 2007. p. 230 51.

Fowler CG, King JL. Sudden bilateral sensorineural hearing loss following speedballing. J Am Acad Audiol. 2008;19(6):461-4.

Freeman SR, Bray ME, Amos CS, Gibson WP. The association of codeine, macrocytosis and bilateral sudden or rapidly progressive profound sensorineural deafness. Acta Otolaryngol. 2009;129(10):1061-6.

Friedman RA, House JW, Luxford WM, Gherini S, Mills D. Profound hearing loss associated with hydrocodone/acetaminophen abuse. Am J Otol. 2000;21(2):188-91.

Ganesan P, Schmiedge J, Manchaiah V, Swapna S, Dhandayutham S, Kothandaraman PP. Ototoxicity: a challenge in diagnosis and treatment. J Audiol Otol. 2018;22(2):59-68.

Ghasemi S, Izadpanahi S, Yaghoubi MA, Brent J, Mehrpour O. Methadone associated long term hearing loss and nephrotoxicity; a case report and literature review. Subst Abuse Treat Prev Policy. 2019;14(1):48.

Harell M, Shea JJ, Emmett JR. Total deafness with chronic propoxyphene abuse. Laryngoscope. 1978;88(9):1518-21.

Helander A, Bäckberg M, Beck O. MT-45, a new psychoactive substance associated with hearing loss and unconsciousness. Clin Toxicol. 2014;52(8):901-4.

Ho T, Vrabec JT, Burton AW. Hydrocodone use and sensorineural hearing loss. Pain Physician. 2007;10(3):467-72.

Iqbal N. Hearing loss in amphetamine users. J Psychoactive Drugs. 2002a Oct;34(4):401-7.

Iqbal N. Recoverable hearing loss with amphetamines and other drugs. J Psychoactive Drugs. 2002b Jun;36(2):285-8.

Ishiyama A, Ishiyama G, Baloh RW, Evans CJ. Heroin-induced reversible profound deafness and vestibular dysfunction. Addiction. 2001; 96(9):1363-4.
Józefowicz-Korczynska M, Lukomski M, Kurnatowski P. Vestibular system in alcohol and drug addicts. Mater Med Pol. 1994 Oct 1; 26(4):123-6.

Kalinec GM, Thein P, Parsa A, Yorgason J, Luxford W, Urrutia R, et al. Acetaminophen and NAPQI are toxic to auditory cells via oxidative and endoplasmic reticulum stress-dependent pathways. Hear Res. 2014;313:26-37.

Konrad-Martin D, Reavis KM, McMillan G, Helt WJ, Dille M. Proposed comprehensive ototoxicity monitoring program for VA healthcare (COMP-VA). J Rehabil Res Dev. 2014; 51(1):81-100.

Kopec KT, Nelson LS. Opioid-induced hearing loss: a trend to keep listening for? Emerg Med. 2012;44(11):4-6.

Kortequee S, Agada FO, Coatesworth AP. Sudden sensorineural hearing loss following intracarotid injection of heroin. Int J Clin Pract Suppl. 2005; (147):128-9.

Kurnatowski P, Garganisz J. Lesions of vestibular organs in opioid addicts: results of the tests recorded by electronystagmography. Eur Addict Res. 1996;2:163-8.

Leache L, Aquerreta I, Moraza L, Ortega A. Morphine-induced hearing loss. Am J Health Syst Pharm. 2016;73(22):1840-3.

Lindeman E, Bäckberg M, Personne M, Helander A. [MT-45: a dangerous and potentially ototoxic internet drug]. Lakartidningen. 2014; 111(40):1712-5. Swedish.

Lonsbury-Martin B, Martin GK. Other ototoxins: aspirin and other nonsteroidal anti-inflammatory drugs, quinine, and macrolides. In: Campbell KCM, editor. Pharmacology and ototoxicity for audiologists. Clifton Park, NY: Thompson Delmar Learning; 2007. p. 18796.

Lupin AJ, Harley CH. Letter: inner ear damage related to propoxyphene ingestion. Can Med Assoc J. 1976;114(7):596.

MacDonald LE, Onsrud JE, Mullins-Hodgin R. Acute sensorineural hearing loss after abuse of an inhaled, crushed oxymorphone extended-release tablet. Pharmacotherapy. 2015; 35(7):e118-21.

Mack KA, Jones CM, Ballesteros MF. Illicit drug use, illicit drug use disorders, and drug overdose deaths in metropolitan and nonmetropolitan areas: United States. MMWR Surveill Summ. 2017 Oct 20;66(19):1-12. Retrieved 2021 Apr 19 from:

Martini A, Milani M, Rosignoli M, Mazzoli M, Prosser S. Audiometric patterns of genetic non-syndromal sensorineural hearing loss. Audiology. 1997 Jul-Aug;36(4):228-36.

Moreira DA, Ganança MM, Caovilla HH. Static posturography in addicted to illicit drugs and alcohol. Braz J Otorhinolaryngol. 2012;78(5): 97-103.

Mozeika AM, Ruck BE, Nelson LS, Calello DP. Opioid-associated hearing loss: a 20-year review from the New Jersey Poison Center. J Med Toxicol. 2020;16(4):416-22.
Mulch G, Handrock M. ["Sudden binaural deafness" after acute heroin intoxication]. Laryngol Rhinol Otol. 1979;58(5):435-7. German.

Nair EL, Cienkowski KM, Michaelides E. The impact of sudden hearing loss secondary to heroin overdose on fitting outcomes. Am J Audiol. 2010;19(2):86-90.

Nicoucar K, Sakbani K, Vukanovic S, Guyot JP. Intralabyrinthine haemorrhage following cocaine consumption. Acta Otolaryngol. 2005. 125(8):899-901.

Novac A, Iosif AM, Groysman R, Bota RG. Implications of sensorineural hearing loss with hydrocodone/acetaminophen abuse. Prim Care Companion CNS Disord. 2015;17(5).

Ntranos A, Shoirah H, Dhamoon MS, Hahn D, Naidich TP, Shin S. Author response: clinical reasoning: a young woman with respiratory failure, hearing loss, and paraplegia. Neurology. 2017;89(9):979.

Oh AK, Ishiyama A, Baloh RW. Deafness associated with abuse of hydrocodone/acetaminophen. Neurology. 2000;54(12):2345.

Oroei M, Peyvandi AA, Mokhtarinejad F. Opioid drugs and sensorineural hearing loss. Addict Health. 2018;10(1):64-6.

Pingarrón I, Bartol R, Vaquero LM, Sánchez Montero F, Muriel C. Hipoacusia en un paciente tras administración de morfina intratecal [Hearing loss in a patient after administration of intrathecal morphine]. Rev Soc Esp Dolor. 2014;21:89-91.

Polpathapee S, Tuchinda P, Chiwapong S. Sensorineural hearing loss in a heroin addict. J Med Assoc Thai. 1984;67(1):57-60.

Ramaioli C, Colagiorgio P, Sağlam M, Heuser F, Schneider E, Ramat S, et al. The effect of vestibulo-ocular reflex deficits and covert saccades on dynamic vision in opioid-induced vestibular dysfunction. PLoS One. 2014; 9(10):e110322.

Ramsay BC. Complete nerve deafness after abuse of co-proxamol. Lancet. 1991;338(8764):446-7.

Rawool V, Dluhy C. Auditory sensitivity in opiate addicts with and without a history of noise exposure. Noise Health. 2011;13(54):356-63.

Repple J, Haessner S, Johnen A, Landmeyer NC, Schulte-Mecklenbeck A, Pawlitzki M, et al. Intravenous methadone causes acute toxic and delayed inflammatory encephalopathy with persistent neurocognitive impairments. BMC Neurol. 2021;21(1):85

Rigby MH, Parnes LS. Profound hearing loss associated with oxycodone-acetaminophen abuse. J Otolaryngol Head Neck Surg. 2008; 37(6):E161-2.

Rigg KK, Rigg MS. Opioid-induced hearing loss and neonatal abstinence syndrome: clinical considerations for audiologists and recommendations for future research. Am J Audiol. 2020;29(4):701-9.

Roland PS, Rutka MD. Ototoxicity. BC Decker Inc; 2004

Rottach KG, Dzaja AE, Wohlgemuth WA, Eggert T, Straube A. Effects of intravenous opioids on eye movements in humans: possible mechanisms. Ann N Y Acad Sci. 2002;956(9):595-7. 
Rybak LP, Ramkumar V. Ototoxicity. Kidney Int. 2007;72(8):931-5.

Saifan C, Glass D, Barakat I, El-Sayegh S. Methadone induced sensorineural hearing loss. Case Rep Med. 2013;2013:242730.

Saunders JE, Luxford WM, Devgan KK, Fetterman BL. Sudden hearing loss in acoustic neuroma patients. Otolaryngol Head Neck Surg. 1995 Jul;113(1):23-31.

Schrock A, Jakob M, Wirz S, Bootz F. Sudden sensorineural hearing loss after heroin injection. Eur Arch Otorhinolaryngol. 2008;265(5): 603-6.

Schweitzer VG, Darrat I, Stach BA, Gray E. Sudden bilateral sensorineural hearing loss following polysubstance narcotic overdose. J Am Acad Audiol. 2011;22(4):208-14.

Shah RK, Blevins NH, Karmody CS. Mid-frequency sensorineural hearing loss: aetiology and prognosis. J Laryngol Otol. 2005 Jul; 119(7):529-33.

Sharma A. A case of sensorineural deafness following ingestion of Ecstasy. J Laryngol Otol. 2001;115(11):911-5.

Shaw KA, Babu KM, Hack JB. Methadone, another cause of opioid-associated hearing loss: a case report. J Emerg Med. 2011;41(6):635-9.
Stenner M, Stürmer K, Beutner D, Klussmann JP. Sudden bilateral sensorineural hearing loss after intravenous cocaine injection: a case report and review of the literature. Laryngoscope. 2009;119(12):2441-3.

Substance Abuse and Mental Health Services Administration. Key substance use and mental health indicators in the United States: results from the 2019 National Survey on Drug Use and Health [internet]. HHS publication no. PEP20-07-01-001, NSDUH series H-55. Rockville, MD: Center for Behavioral Health Statistics and Quality, Substance Abuse and Mental Health Services Administration; 2020. Retrieved 2021 Apr 19 from: https://www. samhsa.gov/data/.

van Gaalen FA, Compier EA, Fogteloo AJ. Sudden hearing loss after a methadone overdose. Eur Arch Otorhinolaryngol. 2009;266(5): 773-4.

Vorasubin N, Calzada AP, Ishiyama A. Methadone-induced bilateral severe sensorineural hearing loss. Am J Otolaryngol. 2013;34(6): 735-8.

Wang N, Xie X. The impact of race, income, drug abuse and dependence on health insurance coverage among US adults. Eur J Health Econ. 2017;18:537-46.
Weich TM, Tochetto TM, Seligman L. Brain stem evoked response audiometry of former drug users. Braz J Otorhinolaryngol. 2012;78(5): 90-6.

Xia W, Liu F, Ma D. Research progress in pathogenic genes of hereditary non-syndromic mid-frequency deafness. Front Med. 2016 Jun;10(2):137-42.

Yamamoto N, Mutai H, Namba K, Morita N, Masuda S, Nishi Y, et al. Prevalence of TECTA mutation in patients with mid-frequency sensorineural hearing loss. Orphanet J Rare Dis. 2017 Dec;12(1): 157.

Yorgason JG, Kalinec GM, Luxford WM, Warren FM, Kalinec F. Acetaminophen ototoxicity after acetaminophen/hydrocodone abuse: evidence from two parallel in vitro mouse models. Otolaryngol Head Neck Surg. 2010;142: 814.

Young YH. Contemporary review of the causes and differential diagnosis of sudden sensorineural hearing loss. Int J Audiol. 2020 Apr; 59(4):243-53.

Zuniga MG, Dinkes RE, Davalos-Bichara M, Carey JP, Schubert MC, King WM, et al. Association between hearing loss and saccular dysfunction in older individuals. Otol Neurotol. 2012 Dec;33(9):1586. 